\title{
Editorials
}

\section{A landmark study of collective action by general practices}

\section{INTRODUCTION}

The independent contractor status of general practice has been a feature of the UK NHS since its inception. Positive consequences have allowed the opportunity for practices to pioneer new aspects of practice and to develop local solutions to local problems. Negative consequences include huge variation in what practices do and what they achieve. The multiplicity of practice voices and the lack of connecting infrastructure have also reduced the impact of general practice as a force for health and health system improvement.

The value of joint working between practices has been demonstrated in many areas, including undergraduate teaching, postgraduate training, primary care research, and service development, but when networks and federations are based on self-selected practices, significant numbers of practices and very large numbers of patients are excluded.

\section{EXCLUDING EXCLUSIONS}

A defining characteristic of primary care is that virtually no patients are excluded. While specialists exclude patients who don't fit, and researchers exclude patients who are difficult to study, general practices are expected to include everyone. In developing general practice and primary care as the solution to tomorrow's problems, the same principle should apply. The NHS achieves population contact and coverage principally via the sum of clinical populations in primary care. When local health systems are developed, it is vital that all such populations are on board.

External inspection and management of primary care often focuses on outliers, whose performance of measurable activities lies outside a statistical range, but this approach is fundamentally limited in what it can achieve, compared with small changes in behaviour in large numbers of practices. The sharing of information, experience and views, to establish and respond to professionally agreed norms is potentially a more powerful tool for system improvement.

\section{REVERSING THE INVERSE CARE LAW}

In this issue, Robson and colleagues ${ }^{1}$ publish a landmark agenda-setting study whose results command attention. On several measures, Tower Hamlets is the most

\section{"The NHS achieves population ... coverage principally via the sum of clinical populations in primary care. When local health systems are developed, it is vital that all such populations are included."}

deprived local authority area in England.2 Yet in 2012/13 without exception reporting, the population had the highest levels in England of blood pressure and cholesterol control in coronary heart disease (CHD) and diabetes. Male mortality rates from $\mathrm{CHD}$, which had been the fourth highest in England in 2008 , fell by $43 \%$ in 3 years, at a much faster rate than observed in similarly high ranking areas.

The study is impressive, but not definitive. It lacks the explanatory value of a randomised controlled trial. What can be learned about how the results were achieved?

For two decades the three east London primary care trusts (PCTs) of Newham, City and Hackney, and Tower Hamlets have supported quality improvements in general practice, providing support for practices with local academic GPs at the helm of clinical effectiveness initiatives. Although $\mathrm{CHD}$ mortality rates remained high, these developments prepared the ground for collective working.

In 2008 all practices in Tower Hamlets without exception were allocated to eight groups of four to five practices serving geographical areas of $30000-50000$ patients. Each network had a network manager, administrative support and an educational budget to deliver financiallyincentivised attainment targets in four care packages, including one for cardiovascular disease. Remarkably, and the study does not make clear how this was done, practices agreed that financial rewards would be distributed on the basis of network achievement and not individual practice achievement.

\section{THE ACTIVE INGREDIENTS}

The intervention had many components, including locally-agreed clinical guidelines, educational meetings, clinical case discussion in multidisciplinary team meetings, administrative meetings to review targets, a network manager for each group of practices, and lead clinicians within each network practice. The local IT system was developed to provide monthly feedback to practices. Over 3 years, the network managers collaborated to build up a sophisticated system of locally-tailored solutions; customising IT searches, register cleaning, patient recall tools, prompts and support to poorly-performing practices.

The total spend per head of population in the Tower Hamlets PCT increased from rank 117 of 151 English PCTs in 2007/8 to rank 7 in 2011/12, covering the increased costs of programmes for cardiovascular disease, diabetes, chronic lung disease, and child immunisation.

Most cardiovascular indicators were already improving at the start of the study period, but they continued to improve in Tower Hamlets, and more so than in two neighbouring PCT areas, where practices individually pursued the same clinical agenda, via conventional local enhanced service arrangements.

The study raises many questions. How important was the preliminary work in establishing the relationships needed for joint working? Were all components of the scheme necessary? Exactly what did it cost, as a proportion of total funding, and could the results be achieved more cheaply? To what extent did all practices engage? Are the results transferable, and if so, how?

\section{SYSTEM DEVELOPMENT TAKES TIME}

A recent King's Fund report reviewed the active ingredients of several initiatives in coordinated care, and highlighted the importance of GP engagement, knowledge, and leadership. ${ }^{3-4}$ Examples from elsewhere can inspire, but bottom-up approaches are necessary to drive local change. Most projects took 6-7years to produce the desired results. The Tower Hamlets programme followed this pattern, with quick results at the end. Perhaps like 


\section{“But power, resource and responsibility will only be transferred if there is evidence of effect.}

compound interest, the benefits of system change accrue not near the beginning but at the end of a period of sustained support. ${ }^{5}$ From a Scottish perspective, the Tower Hamlets programme incorporates many of the recommendations made by GPs at the Deep End for addressing the inverse care law, improving health in deprived areas, and narrowing health inequalities, ${ }^{6}$ including additional resource lalthough not, apparently, for clinical encounters), GP leadership, improved information, shared learning, and administrative support (shifting some of the huge NHS management resource from the centre to the peripheryl.

\section{FUTURE CHALLENGES}

As only $13 \%$ of GP encounters involve QOF conditions, ${ }^{7}$ the disease-based approach of the Tower Hamlets programme does not yet address the wider, unconditional role of general practice in addressing multimorbidity, especially the type of multimorbidity and social complexity that occurs $10-15$ years earlier in deprived areas. $^{8}$ But it is encouraging that cardiovascular aspects of the inverse care law appear reversible, improving outcomes in a short period of time.

Health care is increasingly important as a social determinant of health. If the NHS is not at its best where needs are greatest, inequalities will widen. Addressing the inverse care law is the necessary first step in developing integrated care in deprived areas. But power, resource, and responsibility will only be transferred if there is evidence of effect. Robson and colleagues provide few clear answers to these questions, but by excluding exclusions and developing a model for collective action, they have shown the way.

\section{Graham Watt,}

Norie Miller Professor of General Practice, University of Glasgow, Glasgow.

\section{Provenance}

Commissioned; not externally peer reviewed.

DOI: 10.3399/bjgp14X679561

\section{ADDRESS FOR CORRESPONDENCE}

Graham Watt

General Practice and Primary Care, Institute of

Health and Wellbeing, University of Glasgow,

1 Horselethill Road, Glasgow, G12 9LX.

E-mail: Graham.Watt@glasgow.ac.uk

\section{REFERENCES}

1. Robson J, Hull S, Mathur R, Boomla K Improving cardiovascular disease using managed networks in general practice: an observational study in inner London. $\mathrm{Br} J$ Gen Pract 2014; DOI: 10.3399/bjgp14X679697.

2. Public Health England. 2012 Health profiles. Early deaths: heart disease and stroke. http://unw.apho.org.uk/resource/view. aspx?RID=116446 (accessed 09 Apr 2014).

3. Goodwin N, Sonola L, Thiel V. Co-ordinated care for people with complex chronic conditions. Key lessons and markers for success. King's Fund, 2013. http://www.kingsfund.org.uk/publications/ co-ordinated-care-people-complex-chronicconditions (accessed 8 Apr 2014).

4. Watt G. Looking beyond 'the house of care' for long term conditions. Some patients are at risk of being left outside. BMJ 2013; 347:f6902.

5. Watt G. The tortoise and the hare. $B r J$ Gen Pract 2011; 61(591): 629.

6 Watt, G. What can the NHS do to prevent and reduce health inequalities? Br J Gen Pract 2013; 63(614): 494-495.

7. Information Services Division. Publication report. Practice Team Information (PTI). Annual Update (2011/12). 29 October 2013. http:// unw.isdscotland.org/Health-Topics/GeneralPractice/Publications/2013-10-29/2013-10-29PTI-Report.pdf (accessed 8 Apr 2014).

8. Barnett K., Mercer SW, Norbury, M, et al Epidemiology of multimorbidity and implications for health care, research, and medical education: a cross-sectional study. Lancet 2012; 380(9836): $37-43$. 